\title{
MODELOS DIDÁTICOS NA FORMAÇÃO INICIAL DE PROFESSORES DE FÍSICA: UMA APRECIAÇÃO NA PERSPECTIVA DA ANÁLISE DO DISCURSO
}

\author{
Teaching Models in the initial training of teachers of \\ physics: an analysis from the perspective of discourse analysis
}

\author{
Cassiana Barreto Hygino ${ }^{1}$. Sérgio Arruda de Moura ${ }^{2}$. \\ Marília Paixão Linhares ${ }^{3}$
}

\begin{abstract}
Resumo: O presente artigo é um recorte de uma pesquisa que focaliza a formação inicial de professores de física. Apresentamos a análise de uma atividade realizada com licenciandos da disciplina Estratégias para o Ensino de Física I, que tem como eixo principal o método de estudo de caso, focalizando problemas da prática docente. Foram solicitadas a eles a elaboração e apresentação de uma proposta de ensino, no formato de aula, com conteúdos referentes à primeira série do Ensino Médio. Neste trabalho, analisamos a proposta didática elaborada e apresentada em sala de aula por um dos alunos, bem como o seu texto de reflexão, usando, para isso, a Análise do Discurso de linha francesa. Nosso objetivo é identificar o ethos deste licenciando, ou seja, compreender sua identidade como professor, e investigar, a partir da análise de seu discurso, se as atividades e discussões realizadas ao longo do curso contribuíram com sua evolução profissional.
\end{abstract}

Palavras-chave: Ensino de física. Formação inicial de professores. Análise do discurso.

\begin{abstract}
This article is part of a research programme that focuses on the physics teacher's training and presents an analysis of a proposed activity conducted with future physics teachers enrolled in Strategies for Teaching Physics I. This course has as a major axis the method of case study, focusing on problems of teaching practice. They were asked to prepare and submit a teaching plan, including content, for the first grade of the secondary school. Then we analyzed the methodological proposals prepared and submitted, as well as his critical text of only one of those involved in the research, using Discourse Analysis. Our goal is to identify the ethos of these teachers, what it means to understand his/her identity as a teacher, and to investigate by means of discourse analysis if the activities, as well as the discussions throughout the course, contributed to their professional development.
\end{abstract}

Keywords: Physics education. teachers' initial education. Discourse analysis.

\footnotetext{
${ }^{1}$ Universidade Estadual do Norte Fluminense Darcy Ribeiro (UENF), Centro de Ciências e Tecnologias, Programa Pós-Graduação em Ciências Naturais. Avenida Alberto Lamego, 2000, Parque Califórnia, CEP 28013-602, Campos dos Goytacazes, RJ, Brasil. E-mail: cacahygino@yahoo.com.br

${ }^{2}$ Universidade Estadual do Norte Fluminense Darcy Ribeiro (UENF), Centro de Ciências do Homem, Programa de Pós-Graduação em Cognição e Linguagem, Campos dos Goytacazes, RJ, Brasil.

${ }^{3}$ Universidade Estadual do Norte Fluminense Darcy Ribeiro (UENF), Centro de Ciências e Tecnologias, Programa de Pós-Graduação em Ciências Naturais, Campos dos Goytacazes, RJ, Brasil.
} 


\section{Introdução}

A formação inicial de professores tem sido objeto de muitos estudos no campo do conhecimento profissional docente. Pesquisas têm indicado a necessidade de mudanças no processo formativo dos futuros professores, caracterizado pelo descompasso entre as disciplinas específicas e aquelas dedicadas às práticas pedagógicas (FURIÓ, 1994).

Durante seu processo de formação, os professores acabam perpetuando o ensino vivenciado, ou seja, baseado em modelos tradicionais. Então, como mudar esta realidade? Como esperar uma postura inovadora do futuro professor?

Pesquisas realizadas nos últimos anos evidenciam que a formação inicial deve investir no desenvolvimento reflexivo dos futuros professores, ou seja, formar profissionais capazes de refletir sobre sua prática, enfrentar situações problemáticas de ensino, propor novas estratégias, testá-las e refletir sobre as mudanças alcançadas (SHÖN, 1992; PEREZ-GOMES, 1992).

Para Porlán e Rivero (1998) e García e Porlán (2000), a formação de professores deve se apoiar em quatro aspectos básicos: os problemas práticos dos professores, suas concepções e experiências, as influências de outras fontes de conhecimentos e as inter-relações que se estabelecem entre elas. Dessa forma, os futuros professores se tornariam capazes de: conhecer seu próprio modelo didático pessoal; observar criticamente sua prática e identificar os problemas inerentes a ela; contrastar através de experiências próprias, e com as de outros profissionais, hipóteses de soluções para os problemas identificados; colocar em prática as hipóteses e saber avaliar as mudanças bem como contrastar os resultados obtidos com base na avaliação das hipóteses de partida, e estabelecer conclusões sobre seu modelo didático pessoal.

Nesse sentido, esta pesquisa, apoiando-se nestas orientações, busca responder a seguinte questão: como possibilitar a evolução do conhecimento profissional de futuros professores de física de forma reflexiva, favorecendo a integração entre a teoria e a prática na licenciatura em física?

$\mathrm{Na}$ tentativa de responder esta questão, desenvolvemos atividades investigativas apoiadas no método de estudo de caso (LINHARES; REIS, 2008) na disciplina Estratégias para o Ensino de Física I. Na disciplina, os futuros professores trabalharam dois estudos de caso sobre problemas práticos da profissão docente, e elaboraram propostas de ensino com base nos estudos realizados e as apresentaram no formato de aula para o restante da turma. Após as apresentações, os licenciandos tiveram a oportunidade de identificar os problemas de sua atuação e refletir sobre eles, a partir de discussões em grupo e de um texto elaborado por eles. Propomos, neste trabalho, a análise de uma aula sobre o conteúdo "máquinas simples" apresentada por um licenciando para sua turma de Estratégias para o Ensino de Física I, além da análise do texto produzido por ele como uma reflexão sobre sua prática.

A análise foi embasada no conceito de modelos didáticos, que, de acordo com García Pérez (2000), refletem a atuação do professor frente ao processo de ensino e aprendizagem e são delimitados em quatro enfoques distintos: o tradicional, o tecnológico, o espontaneísta e o alternativo.

Procurando nos aproximar de uma abordagem mais qualitativa da reflexão do professor sobre suas práticas, representadas aqui pelo seu discurso, enfocamos a imagem pessoal que o professor constrói na interação com seus alunos na cena mesma em que este emerge, 
Modelos didáticos na formação inicial ...

que é uma sala de aula. Aquela imagem emerge do caráter que ele expressa, que, na retórica clássica, se conceitua como ethos.

\section{Modelos didáticos na formação inicial de professores}

Os modelos didáticos em uma dimensão educativa podem ser entendidos como as crenças de professores sobre o ensino e a aprendizagem, as quais se manifestam por meio do discurso, das ações e do comportamento do professor. Como veremos mais adiante na análise em si dos dados, é a partir do discurso que perceberemos manifestas as questões cruciais inscritas na formação do professor, entre as quais o ethos, no caso, de professor em uma prática condizente com um modelo específico que adotará para si.

Mapear e analisar estes modelos didáticos manifestados por professores em formação inicial e continuada pode contribuir com reflexões sobre o seu processo de formação. Como afirmado anteriormente, existem quatro modelos didáticos que correspondem à atuação dos professores frente ao processo de ensino-aprendizagem (GARCÍA PÉREZ, 2000).

O modelo tradicional focaliza o conteúdo, e se caracteriza pela ênfase na transmissão destes do professor para o aluno. Neste modelo, o contexto social e os interesses dos estudantes são desconsiderados. A metodologia para a condução das atividades se deve estritamente a uma postura ativa do professor, que retém os conhecimentos e deve transmiti-los, e de uma postura passiva dos estudantes, que devem absorver todo o conteúdo estudado. As atividades priorizam a memorização de informações, nomes, fórmulas. Os conhecimentos são fragmentados e não apresentam qualquer relação com a realidade dos alunos. A avaliação valoriza a memorização dos conceitos transmitidos e ocorre através de exames e provas pontuais.

O modelo tecnológico procura inovar o modelo tradicional, incorporando, ao currículo da escola: atividades práticas, materiais didáticos atualizados e um rigoroso detalhamento dos planejamentos de ensino. A metodologia procura obter maior eficiência do processo de ensino. A avaliação tem como objetivo quantificar a aprendizagem e verificar a eficiência desta sistemática de ensino. Neste modelo, o aluno também tem uma participação passiva, devendo participar das atividades programadas.

No modelo espontâneo, a ênfase está nas ideias e interesses dos alunos. A realidade dos alunos é levada em consideração em todas as atividades. Neste modelo, as atividades são flexíveis e valorizam o desenvolvimento de atitudes e autonomia dos estudantes. Os conteúdos trabalhados consideram os interesses dos alunos, e a avaliação focaliza o desenvolvimento deles. O professor tem o papel de líder social e afetivo, seu trabalho ocorre essencialmente no campo da prática, levando em consideração sua experiência.

Já o modelo alternativo propõe um ensino no qual tanto alunos quanto professores exercem um papel ativo. Enfatizam-se as situações-problema que exigem dos alunos posturas investigativas, nas quais devem elaborar hipóteses e propor soluções. As atividades são contextualizadas com temas socialmente relevantes e com incentivo da atuação dos alunos. A avaliação tem como objetivo identificar as dificuldades dos alunos e promover reflexões sobre a evolução deles.

Para o desenvolvimento da pesquisa, nos guiamos pelo modelo de formação, destinado à progressão do conhecimento profissional, de Porlán e Rivero (1998). Para investigar os 
Hygino, C. B.; Moura, S. A.; Linhares, M. P.

modelos didáticos presentes na aula do licenciando, adotamos como referencial de análise os pressupostos de García Pérez (2000).

\section{A disciplina Estratégias para o Ensino de Física I: público e atividades de ensino}

O contexto desta pesquisa está situado no desenvolvimento de um conjunto das três disciplinas de Estratégias para o Ensino de Física I, II e III, oferecidas em três semestres alternados, para alunos do $3^{\circ}, 5^{\circ}$ e $7^{\circ}$ períodos de um curso de Licenciatura em Física. Estas disciplinas têm como principal objetivo associar teoria e prática e conhecimentos científicos da área de física e conhecimentos pedagógicos. Neste recorte da pesquisa, analisaremos os dados coletados na primeira das três disciplinas.

As atividades didáticas destas disciplinas se desenvolvem em torno do método de estudos de caso. De acordo com Sá, Francisco e Queiroz (2007), este método é uma variante da Aprendizagem Baseada em Problemas (ABP) e foi desenvolvido com o objetivo de possibilitar, aos estudantes, o trabalho com problemas reais. Os estudos de caso se apresentam como narrativas ou como um relato de situações problemáticas que, neste caso, se constituem em problemas da prática docente e requerem uma solução. Neste sentido, os licenciandos devem propor soluções aos problemas apresentados, incentivando-os, deste modo, a elaborar hipóteses e tomar decisões relacionadas a sua profissão. Os alunos devem propor soluções partindo de suas ideias prévias e aprofundá-las ao longo de três passos característicos do processo didático do método de estudos de caso. Durante o desenvolvimento dos passos, os alunos articulam conhecimentos teóricos e práticos com a finalidade de proporem novas soluções baseadas nos novos conhecimentos adquiridos.

No primeiro passo, os estudantes expõem suas ideias sobre um ou mais problemas apresentados no estudo de caso; no segundo, são encaminhados textos para leitura e confecção de resenhas, quando, também, são realizadas discussões e atividades práticas em sala de aula; no último passo, os estudantes devem propor novamente soluções para os problemas levantados no estudo de caso, contudo levando em consideração os conhecimentos adquiridos durante o processo (LINHARES; REIS, 2008).

Os dados aqui analisados são referentes ao trabalho realizado no primeiro semestre letivo de $2011 \mathrm{com}$ cinco alunos regularmente matriculados em Estratégia para o Ensino de Física I, disciplina obrigatória com carga horária de 34 horas. As aulas ocorreram uma vez por semana, no turno da noite, com duas horas-aula de duração de uma hora cada. A professora da turma e primeira autora deste trabalho foi quem orientou as atividades desenvolvidas ao longo da disciplina.

Nesta disciplina, foram desenvolvidos dois estudos de caso: Uma aula de Física e Reflexões sobre o currículo de física. No primeiro, buscou-se compreender os modelos didáticos pessoais de cada licenciando, observando suas ideias sobre o processo de ensino-aprendizagem, no que diz respeito: aos objetivos do ensino de física, que conteúdos devem ser escolhidos, qual a melhor metodologia a ser adotada e como deve ser a avaliação. No segundo, objetivou-se compreender a visão dos futuros professores sobre o currículo de física e quais sugestões apresentavam para melhorá-lo. 
Durante o desenvolvimento destes estudos de caso, os alunos fizeram leituras e pesquisas sobre o assunto. Além disso, os licenciandos tiveram a oportunidade de assistir a aulas com professores do sistema de Ensino Básico da região, a fim de refletirem sobre as aulas que estes lecionam e de conhecerem e refletirem sobre resultados importantes de pesquisas acadêmicas sobre o ensino de física, a partir da leitura de artigos da área de ensino de ciências.

No fim da disciplina, os futuros professores deveriam elaborar uma proposta de ensino e apresentar uma aula referente ao conteúdo da primeira série do Ensino Médio. As propostas de aulas deveriam levar em consideração as discussões e conhecimentos adquiridos durante o desenvolvimento da disciplina.

$\mathrm{Na}$ Estratégia para o Ensino de Física I, os licenciandos escolheram a metodologia e a sequência de sua aula livremente, ou seja, sem a interferência do professor-orientador. Após as apresentações, cada licenciando elaborou um texto como uma reflexão sobre sua aula, apontando as dificuldades, o que consideraram importante e o que mudariam.

Todos os licenciandos desta disciplina tiveram a oportunidade de conhecer, refletir e discutir os aspectos relevantes do ensino de física, na tentativa de melhorar o aprendizado dos estudantes e inovar suas práticas.

\section{A pesquisa: os dados e a análise}

Consideramos que os procedimentos vinculados às abordagens qualitativas de pesquisa se mostraram mais adequados para o tipo de investigação que nos propomos empreender. Para Bogdan e Biklen (1994), cinco principais características identificam uma investigação de natureza qualitativa: i) a fonte direta de dados é o ambiente natural; ii) a pesquisa é descritiva; iii) os investigadores interessam-se mais pelo processo que pelos resultados ou produtos; iv) os investigadores tendem a analisar os seus dados de forma indutiva, e v) o significado é de importância vital em investigações dessa natureza. Serão analisados, nesta pesquisa, dados provenientes da gravação em áudio e vídeo da aula apresentada pelo licenciando $\mathrm{F}^{4}$ e do texto elaborado pelo próprio licenciando como uma reflexão sobre sua prática. A escolha pela aula deste licenciando se deve unicamente à ordem de apresentações, já que este foi o primeiro a apresentá-la. Em comunicações futuras, serão apresentadas as análises das aulas dos outros licenciandos.

As gravações foram autorizadas por todos os envolvidos, esclarecidos os objetivos da pesquisa, guardando o seu necessário anonimato. Após a gravação da aula, foi realizada sua transcrição.

Analisaremos, primeiramente, a transcrição da aula do licenciando F e, em seguida, seu texto de reflexão. Para a análise, seguimos as orientações da Análise do Discurso de linha francesa como proposta por Maingueneau (2011). De acordo com este autor, o discurso é o

\footnotetext{
${ }^{4}$ Por questões éticas, preservamos os nomes dos licenciandos. Chamaremos o licenciando que aplicou e planejou a aula de licenciando F, e os demais licenciandos envolvidos na pesquisa, por nomes fictícios.
} 
lugar em que língua e ideologia se relacionam, sendo efeito de sentidos entre locutores. Não há discurso sem sujeito, nem sujeito sem ideologia e, ainda, não há discurso que não se relacione com outros, ou seja, um dizer está sempre em relação com outros dizeres. O autor desenvolve ainda a relevância do ethos discursivo quando, a partir da orientação da retórica aristótelica, concebe, nos processos de interlocução, as estratégias de constituição da imagem.

Procuraremos identificar, na aula do licenciando F, o ethos que constituirá a identidade do professor. Maingueneau (2011) afirma que o ethos é revelado pela enunciação e mostra os traços do orador em relação a quem o ouve, ou seja, o ethos está ligado à imagem construída pelo co-enunciador. $\mathrm{O}$ ethos é, então, construído a partir do momento em que o enunciador se mostra através de seu discurso, ou seja, o ethos toma forma durante a atividade enunciativa e instaura a imagem daquele que enuncia. A partir desta definição do ethos, iremos identificar: a postura do professor, a representação e apropriação que este faz do que foi discutido durante o processo realizado, que recursos utilizou para construir sua identidade.

Em nossa análise, também caracterizaremos as cenas de enunciação que, segundo Maingueneau (2011), se constitui em três: "cena englobante", que define o tipo de discurso; "cena genérica", que define o papel do discurso para o coenunciador, ou seja, é o espaço no qual o enunciado adquire sentido; e "cenografia", que representa o desenvolvimento da enunciação, aquela que é criada pelo próprio discurso. Por fim, verificaremos o enunciado, que é o próprio discurso do licenciando e a enunciação, o que vai além deste discurso, os recursos utilizados e os interdiscursos que condicionaram os enunciados. A partir desta análise, poderemos identificar os modelos didáticos presentes na prática deste licenciando.

\section{Análise da aula}

A aula gravada e transcrita propõe um discurso didático, no qual o professor ensina um determinado conteúdo aos seus alunos. Claramente, se enuncia uma cena englobante que faz uso de todos os recursos que caracteriza o discurso didático. A cena genérica, por sua vez, é a de uma aula de física específica dirigida a um coenunciador, que deve ocupar o lugar de um aluno que sabe que terá aulas de conteúdos de física com aquele professor. Assim, a cenografia se constitui de uma aula-teste, que simula uma aula de física real. Neste caso, o enunciador deve se comportar como um professor de física que, ao abordar o conteúdo de máquinas simples, tenta propor uma aula inovadora, ou seja, que busca superar um ensino predominantemente transmissivo. Em sua aula, também precisa levar em consideração as orientações dos Parâmetros Curriculares Nacionais (PCNs) (BRASIL,1999). O enunciador também sabe que sua aula está sendo avaliada pelo seu professor.

A seguir, apresentaremos a análise de alguns trechos extraídos da transcrição da aula do licenciando F, com o objetivo de identificar, em seu discurso, sua identidade de professor, que ele tenta construir, considerando conceitos tais como sujeito e ideologia.

Licenciando F: "Bom, a aula que eu vou dar é sobre máquinas simples, antes da gente começar a gente precisa saber o que são máquinas simples, qual a ideia que vocês têm do que seja uma máquina simples?”. 
É feito um silêncio em sala de aula e o licenciando prossegue:

Licenciando F: "Qual a diferença de uma máquina simples para um carro, o carro é uma máquina, né? Qual a diferença de uma máquina simples para um carro? Por que o carro não é uma máquina simples?”.

Nestes trechos, o licenciando F apresenta sua proposta e o conteúdo que será abordado naquela aula. E tenta estabelecer uma postura dialógica com os estudantes, no momento em que busca compreender suas ideias prévias sobre o conteúdo. No entanto, como não obtém retorno, o licenciando $\mathrm{F}$ tenta trazer à tona as ideias dos alunos através da comparação entre uma máquina simples e um carro. Neste momento, notamos que o licenciando $\mathrm{F}$ tenta organizar sua intervenção pedagógica, apontando para uma aproximação com um modelo alternativo, ao trazer problemas aos estudantes e, também, por tentar trabalhar com suas ideias iniciais, distanciando-se, desse modo, de um ensino tradicional, que percebe o aluno com uma página em branco, desprovido de qualquer tipo de conhecimento sobre o assunto.

No trecho, mostrado a seguir, o licenciando $F$ faz uso do quadro de giz para exemplificar o que está tentando explicar.

Licenciando F: "Eu tenho um corpo com uma determinada massa, eu amarro uma corda nele e passo aqui na roldana e aqui eu vou ter uma força para baixo na mesma direção da força-peso desse corpo. $\mathrm{E}$ a corda, o que que ela vai fazer?".

Licenciando F: "A corda é um dispositivo que a gente usa ela para transmitir a força. Isso daqui é uma corda, se eu aplico uma força aqui nessa direção, essa força vai ser transmitida por todos os pontos da corda e aqui vai surgir uma força nessa mesma direção, então, se eu puxo essa corda para baixo essa força vai ser transmitida até chegar aqui e vai esse corpo para cima, taí um exemplo de uma máquina, uma corda com uma roldana".

Ao analisarmos este trecho da aula do licenciando $\mathrm{F}$, verificamos a importância do papel do quadro de giz para sua aula. O professor faz desenhos, escreve símbolos e alguns termos que quer destacar. Após este registro no quadro, o licenciando F solicita aos alunos que também percebam as relações que desenhou no quadro. Isso é feito pelo emprego de dêiticos tais como: "isso daqui", "aqui", "taî", acompanhados de intensa gesticulação durante a maior parte do tempo da aula, como apontar, frequentemente com o dedo para um registro escrito no quadro de giz sobre o qual ele quer chamar a atenção. Aqui podemos perceber uma tendência mais tradicional de ensino, com o professor expondo, no quadro, suas ideias para que os alunos possam assimilá-las.

A seguir, outro trecho retirado da aula do licenciando F que traz, mais uma vez, a tentativa de um diálogo em sala de aula. 
Licenciando F: "Mas tem um outro tipo de máquinas simples também que é... muito utilizado no nosso dia-a-dia que a gente vê com tanta frequência que a gente nem presta atenção nos conceitos físicos que tão envolvidos ali naquela máquina, alguém poderia dar... alguém tem alguma ideia, poderia dar um exemplo de alguma outra máquina simples?"

E o aluno Breno, participando da aula, responde: "Uma alavanca?"

Nesse trecho, o licenciando F tenta dialogar com os estudantes e também trazer elementos do cotidiano para exemplificar os conceitos que estão sendo estudados em sala de aula. Esta aproximação com o cotidiano dos estudantes mostra que o licenciando tenta atender uma das orientações presentes nos PCNs de física (BRASIL, 1999), documento discutido durante o desenvolvimento da disciplina. O licenciando, neste aspecto, apresenta marcas de um modelo espontaneísta, ao discutir os conteúdos de forma a proporcionar, aos alunos, uma compreensão de sua realidade.

Em seguida, apresentamos outro trecho da aula, no qual o licenciando utiliza o recurso de demonstrações experimentais.

Licenciando F: "Dá pra gente fazer uma máquina simples, dá pra gente fazer um exemplo aqui com uma régua e um peso qualquer um celular, uma borracha, se eu tenho aqui... a mesa aqui vai ser o meu ponto de apoio".

Em seguida, o licenciando F utiliza objetos e a mesa do professor para fazer sua demonstração:

Licenciando F: "E aqui eu tenho uma massa, se eu faço uma força aqui, que que vai acontecer? Eu vou levantar do outro lado mas eu chego isso aqui mais pra cá/ aí boto na metade, por exemplo o que que vai acontecer com essa força que eu tenho aqui?”.

E então, novamente, o aluno Breno responde: "Vai diminuir".

No trecho acima, o licenciando se utiliza de objetos simples, como uma régua e um celular apoiados em uma mesa, na tentativa de exemplificar, de forma prática, os conceitos que estão sendo estudados. Diferentemente do início da aula, na qual o licenciando expõe no quadro os conceitos, neste momento ele lança mão de recursos disponíveis na tentativa de construir tais conceitos em conjunto com os alunos. Além disso, o licenciando também desafia os alunos a perceberem o que acontecerá com a força que ele aplica na régua. Nesse momento, os alunos são estimulados a formularem hipóteses de soluções para o questionamento levantando, rompendo com um ensino essencialmente transmissivo, no qual o professor fala e os alunos apenas ouvem, sem qualquer momento para reflexão sobre os conceitos estudados, aproximando, mais uma vez, do modelo alternativo de ensino.

No trecho a seguir, o licenciando F utiliza objetos do cotidiano do aluno para exemplificar os tipos de alavancas que está explicando. 
Modelos didáticos na formação inicial ...

Licenciando F: "Um exemplo dessa interpotente quando a força tá no meio, eu tenho uma pinça, uma pinça como é que ela funciona? Eu tenho aqui um ponto fixo né? e eu vou pressionar ela aqui".

O licenciando F decide fazer desenhos no quadro:

Licenciando F: "no meio, então, vai surgir uma força aqui que vai agir sobre alguma que eu 'tiver' querendo segurar aqui, então, aqui vai ser minha força, resiste aqui a minha força potente e o ponto de apoio 'tá' aqui, então, a força potente no meio interpotente, alguma dúvida até aqui?".

Neste trecho, o licenciando F faz uso da explicação do funcionamento de uma pinça para exemplificar os conceitos em estudo. Mais uma vez, o licenciando utiliza elementos presentes no cotidiano dos estudantes para estudar os conceitos. Apresentando um modelo espontaneísta de ensino. Desse modo, o estudo de conceitos da física são percebidos pelos alunos como importantes para compreender o funcionamento de simples objetos a sua volta.

O trecho seguinte apresenta um recurso utilizado pelo licenciando para o seu trabalho com o conteúdo de máquinas simples.

Licenciando F: "Então eu tenho alguns exemplos aqui agora... eu vou pedir para vocês identificarem que tipo de alavanca que é, se é interfixa interresistente e interpotente".

$\mathrm{O}$ licenciando F, neste momento, liga uma televisão e apresenta algumas imagens por ele selecionadas.

O licenciando selecionou algumas imagens de objetos como: alicate, pinça, guilhotina de cortar papel, quebra-nozes; e, também, de partes do corpo humano, como: o crânio, braço e antebraço, para que os alunos pudessem identificar as forças atuantes em cada um dos objetos. Estas imagens foram retiradas da internet e armazenadas em um pendrive. Na sala de aula, com auxílio de uma televisão, que permite a entrada deste tipo de equipamento, apresentou as imagens aos alunos.

O uso deste recurso didático proporcionou uma dinâmica maior na sala de aula e uma participação maior dos estudantes, já que estes se sentiam desafiados a descobrirem que tipos de forças atuavam em cada uma das imagens apresentadas. Notamos, aqui, a presença de vários tipos de recursos, utilizados pelo licenciando $\mathrm{F}$, com a finalidade de contribuir com a construção dos conhecimentos dos estudantes, uma tentativa de aproximação com o modelo alternativo.

A seguir, apresentaremos a dinâmica desencadeada em sala de aula decorrente do uso das imagens.

Licenciando F: "Breno".

[Risos ao verem a imagem de um crânio]

Professor: "Um pouquinho de biofísica agora". 
Breno: "Nossa::".

Licenciando F: "Mas as forças 'tão' indicadas, aí é só ver de onde as forças tão saindo ...".

Philip: "Pra equilibrar o... crânio".

Licenciando F: "Isso aqui é pra equilibrar o peso do crânio, o peso 'tá' concentrado mais ou menos na parte da frente o crânio, 'tá' equilibrado na segunda coluna vertebral mais ou menos aqui no meio".

Breno: "Ah, ta".

Professor: "Então, pra você levantar o músculo que 'tá' aqui por trás da... entre o crânio e a coluna, o músculo que vai levantar...".

Breno: "ah, tá! essa vai ser uma interfixa".

Professor: "Interfixa".

Philip: "essa é legal, interpotente".

Licenciando F: "Essa daqui do braço, se você analisar, nós temos osso no braço inteiro, é só você analisar que o músculo do bíceps seria a... a força potente, aqui o apoio, aqui a força de resistência, aqui seria a interfixa mas também tem os músculos daqui do ante braço, mas se você analisar, só essa daqui seria o caso de inter potente".

Licenciando F: "Guilhotina de cortar papel".

Breno: "essa vai ser uma interresistente".

Licenciando F: "Interresistente vai colocar o papel aqui ... vai levantar ela, colocar o papel aqui no meio, o ponto de apoio, 'tá' aqui, quando você pressiona a força de resistência vai surgir ali no centro".

O licenciando F também faz uso, em sua aula, do recurso da história da ciência para tentar contextualizar o conteúdo e tratar de alguns exercícios.

Licenciando F: "Agora eu tenho um... preparei um textinho aqui... falando sobre... ele mostra um pouquinho do... da importância do conhecimento dessas...”.

O licenciando F, agora, entrega um texto, por ele preparado, para os alunos.

Licenciando F: "Dessas máquinas. Alguém aqui já ouviu essa frase? Me dê um ponto de apoio e uma alavanca que eu moverei o mundo? Então. Essa é uma frase de Arquimedes, ele também ficou impressionado quando ele descobriu essa eng enhosidade da alavanca, e ele ficou tão empolgado que ele soltou essa frase: 'Me dê uma alavanca e um ponto de apoio que eu moverei o mundo', mas toda vez que a gente fala de Arquimedes a gente sempre fala dessa história mas... a gente vai ver por que ele ficou tão empolgado assim com a alavanca. Alguém pode ler o texto aí pra gente?”. 
Modelos didáticos na formação inicial ...

Os estudantes fazem silêncio na sala de aula:

Licenciando F: "Breno, você que lembrou da frase?".

Breno: "é isso que eu ganho por lembrar dessa frase".

Então, Breno lê o texto.

Licenciando F: "Alguém mais? Continua, Philip.

Então o que vocês acharam do texto?".

Licenciando F: "Tito?".

[Risos]

Licenciando F: "Sabia dessa história, Tito?".

Tito: "Não, não sabia, gostei de saber que ele ajudou na guerra lá, interessante".

Philip: "desenvolve tecnologias, né?".

Licenciando F: "Você acha que se você estivesse no lugar de Arquime-

des você empregaria esses conhecimentos de alavanca na...".

Guto: "eu patentiaria".

[Risos]

Tito: "é bom, né?".

Breno: "Mas levou o nome dele, tá?".

No trecho, percebemos que o próprio licenciando preparou o texto sobre a história de Arquimedes. Apesar de sua utilização ter sido de forma anedótica, ou seja, reforçando a ideia de um cientista genial, que sozinho conseguiu descobrir coisas maravilhosas, o uso deste recurso proporcionou interesse e participação da turma. Além disso, o licenciando, ao pedir que os estudantes lessem o texto, estimulou a leitura em aulas de física, que, comumentemente, são vistas como aulas voltadas apenas para o formalismo matemático, nas quais os alunos devem apenas memorizar fórmulas e substituir números nelas.

Nos trechos seguintes, apresentaremos o mecanismo de avaliação escolhido pelo licenciando F em sua proposta didática.

Licenciando F: "Bom, agora eu tenho mais um... um exerciciozinho... dois exercícios dá pra gente resolver agora na aula mesmo é... pra gente comprovar... relembrando como a gente viu o texto do Arquimedes... então ainda... lembrando a história do Arquimedes, primeiro a história da alavanca e depois a história do... do empuxo, eu queria que vocês descobrissem... dissessem pra mim, ou melhor, vocês montem o esquema e resolvam o seguinte problema, ele disse que dado um ponto fixo ele poderia mover a Terra".

Tito: "é pra entregar? Pode fazer aqui atrás?".

Licenciando F: "Pode. Dado um... um ponto... um ponto de apoio fixo, ele poderia mover a Terra, considerando que a massa da Terra...". [Escreve no quadro] 
Hygino, C. B.; Moura, S. A.; Linhares, M. P.

Licenciando F: "Massa da Terra é igual a seis vezes... seis vezes dez elevado a vinte quatro quilogramas, então a gente tem a Terra aqui redonda...".

[risos]

Licenciando F: "A terra aqui, vamos supor que a lua esteja por aqui e a lua sirva como um ponto fixo, ela... a distância da Terra pra lua vale... quatro vezes dez a seis metros e, considerando que o Arquimedes conseguiria fazer uma... uma força de sessenta newtons, então a força dele, que é no nosso caso a força potente, é igual a sessenta newtons, qual que vai ser o comprimento dessa alavanca pra que ele consiga pelo menos equilibrar a Terra?".

Ao analisarmos os trechos acima, percebemos que o licenciando $F$ preferiu a avaliação ao final da explicação dos conteúdos e buscou averiguar, a partir de exercícios com aplicação do formalismo matemático, se os estudantes conseguiram compreender os conceitos estudados na aula. Esse tipo de avaliação é típico de aulas tradicionais. No entanto, o problema teve um contexto e representou um desafio para os estudantes.

A partir das análises realizadas sobre alguns trechos retirados da gravação da aula do licenciando F, podemos perceber que o ethos deste licenciando reflete um professor que já incorpora inovações em sua prática, que, em alguns momentos, atende orientações presentes em documentos oficiais da Educação Básica, como, por exemplo, o uso de elementos do cotidiano, com a finalidade de aproximar os conceitos científicos estudados e a realidade do aluno. Mas, ao mesmo tempo, apesar de buscar compreender as ideias prévias iniciais dos estudantes, não tenta trabalhar com elas de modo que os alunos construam e reconstruam seus conhecimentos. O licenciando dispõe de diversos recursos didáticos para trabalhar os conteúdos em sala de aula, no entanto, sua postura é de um administrador, e os alunos devem cumprir as atividades propostas. Sua avaliação apresenta-se de forma bastante tradicional, buscando verificar o conhecimento adquirido pelos alunos. Portanto, o professor apresenta uma identidade que se aproxima de modelos didáticos mais inovadores e, ao mesmo tempo, mais tradicionais.

Depreende-se desta análise que a incorporação, no planejamento de aula, de diferentes recursos didáticos, da consideração das ideias iniciais dos alunos e do uso do diálogo demonstra que o licenciando F procurou inovar sua prática. Este fato evidencia que as discussões, leituras e a atividade investigativa proposta (planejamento e execução de uma aula) são fatores relevantes para a tomada de consciência e evolução do conhecimento docente. No entanto, em alguns momentos, o licenciando $\mathrm{F}$ retoma métodos mais tradicionais, o que se justifica pelo fato de que os futuros professores apresentam concepções didáticas já incorporadas a sua prática docente, visto que, durante toda a sua formação, foi exposto a contextos escolares tradicionais.

No entanto, concordamos com Porlán e Rivero (1998), no sentido de que a pretensão não é substituir o conhecimento dos professores, mas melhorar, progressivamente, suas ideias preexistentes e a forma como pensam sobre seu modo de ensinar, ou seja, propomos uma evolução do conhecimento profissional docente. 


\section{Análise do texto}

Passaremos, agora, à análise do texto produzido pelo licenciando como uma reflexão sobre sua aula. De acordo com Oliveira (2009), o processo de refletir sobre posições assumidas, neste caso, a posição de professor, implica trazer à tona noções de subjetividade e identidade. Este processo contribui com a autopercepção e autorreconhecimento de seus procedimentos.

Assim como Cristóvão (2002), acreditamos que criar oportunidades para que os licenciandos possam refletir e registrar sua prática contribui para: a construção da autoconfiança, percepção a respeito do processo ensino-aprendizagem, e construção de novos significados para a prática de ensino.

Buscaremos, agora, identificar, no discurso do licenciando, a manifestação de sua identidade de professor, concretizada em um texto produzido por ele. O licenciando F dividiu seu texto de reflexão em três partes. Na primeira, acredita que existe a necessidade de controlar o uso do quadro de giz e o hábito, sempre criticado, de falar de costas para os alunos, conforme descrito a seguir:

Licenciando F: "Utilização do quadro - no início da aula eu mantive uma certa coerência ao utilizar o quadro, mas no final comecei a escrever em uma parte e terminar na outra".

Licenciando F: "Não falar de costas - várias vezes eu virei de costas para explicar enquanto escrevia, seria mais correto explicar e depois escrever ou escrever e depois explicar".

É interessante observar que, em sua reflexão, o licenciando demonstra acreditar que sua desenvoltura, ou seja, sua forma de agir com a turma interfere na aprendizagem dos alunos. Desta forma, o licenciando identifica-se com a imagem do professor como responsável pelo envolvimento do aluno com o conhecimento em estudo e com sua participação na aula. Sendo assim, o discurso do licenciando sinaliza, como ressalta Oliveira (2009), que, de fato, os atos do professor influenciam diretamente no objetivo de todo o ensino e na aprendizagem dos alunos, o que reforça a ideia de construção de um ethos de professor dentro de uma cena enunciativa específica, a sala de aula, no caso.

$\mathrm{Na}$ segunda parte, o licenciando aponta três pontos que poderiam ser melhorados.

Licenciando F: "Diálogo com alunos - no início da aula eu tentei dialogar com os alunos, mas eles não corresponderam da maneira que eu esperava. Ao invés de desistir eu deveria tê-los provocado mais".

Licenciando F: "Experimento melhor elaborado - o experimento utilizando a régua e o celular teve a vantagem de mostrar a simplicidade da alavanca, mas se eu tivesse preparado melhor com dois objetos de massa conhecida, e colocado os alunos para fazer eles poderiam encontrar a relação (Fp.a=Fr.b) por eles mesmos". 
Hygino, C. B.; Moura, S. A.; Linhares, M. P.

Licenciando F: "Exercícios - os exercícios em geral foram muito bons, na primeira parte sobre alavancas eu recorri ao vídeo e trouxe bons exemplos para serem analisados, e os dois últimos, um sobre empuxo e o outro sobre alavanca, eu relacionei à história da ciência que havíamos acabado de comentar. Mas eu poderia ter trazido ainda objetos que funcionam como alavancas (tesouras, alicates, pinças...) e colocado nas mãos dos alunos para que analisassem e descrevessem o funcionamento".

Nesta parte da reflexão, como podemos notar, o licenciando aponta suas falhas e, ao mesmo tempo, tenta justificá-las, e sugere algumas mudanças de melhoria. A primeira falha apontada pelo licenciando se refere à tentativa de manter a interação com os alunos; ao perceber que não conseguiu, admite que deveria ter continuado a tentar. $\mathrm{O}$ licenciando mostra indícios de que considera importante valorizar e utilizar as ideias dos alunos. Talvez essa postura crítica tenha sido influenciada pelas discussões realizadas na disciplina. Esta postura de tentar trabalhar com as ideias dos alunos, buscando construir os conhecimentos, já mostra um amadurecimento do licenciando, aproximando-o de um modelo alternativo de ensino.

Outro ponto ressaltado pelo licenciando está ligado ao uso mais adequado do experimento. Primeiramente, o licenciando considera que o experimento contribuiu com a aprendizagem dos alunos. No entanto, acredita que poderia ter feito algumas mudanças, e cita algumas possibilidades, como a utilização de massas conhecidas, pois acredita que, dessa forma, facilitaria a aprendizagem de relações matemáticas. E, ainda, proporia que os alunos também realizassem o experimento. Dessa forma, os estudantes poderiam chegar as suas próprias conclusões sobre os conceitos estudados. Neste trecho de sua reflexão, percebemos que o licenciando acredita que os alunos devem adquirir uma postura ativa em sala de aula, inclusive, com o uso de experimentos, superando a ideia de que somente o fato de observar a realização de um experimento é suficiente. O licenciando entende que os alunos precisam ser desafiados e estimulados a criar hipóteses de solução para os problemas levantados.

$\mathrm{O}$ último destaque foi em relação aos exercícios. O licenciando acredita que os exercícios por ele elaborados foram bons. Mas acredita que se houvesse levado para a sala de aula objetos como alicate, pinça ou tesoura, poderia ter facilitado, ainda mais, a aprendizagem dos alunos. Nesse momento, o licenciando percebe que é importante estreitar os conceitos aprendidos com o cotidiano dos alunos. Isto indica que o licenciando busca atender as orientações dos PCNs (BRASIL, 1999), tema discutido durante a disciplina.

A seguir, o trecho de conclusão do licenciando.

Licenciando F: "Apesar de não ter se aproximado do modelo alternativo que buscamos, a aula foi proveitosa, o recurso a novas tecnologias, experimentos e a história da ciência são pontos positivos que devem ser mantidos. A aula pecou no aspecto da formação integral do aluno como cidadão capaz de analisar e opinar sobre as questões à sua volta, mas o objetivo de transmitir os conceitos físicos presentes nas máquinas simples do nosso cotidiano foi alcançado, pudemos perceber isso através dos exercícios aplicados em aula”. 
Como conclusão, o licenciando considera que não se aproxima do modelo alternativo que buscava. Essa consideração se deve às aulas na disciplina de Estratégia, quando foram discutidos tipos de modelos didáticos. No entanto, apesar desta não-proximidade, o licenciando tenta destacar que sua aula obteve alguns pontos positivos que acredita que devem ser levados em consideração, como o uso de tecnologias, da história da ciência e do experimento. Percebemos que o licenciando tenta incorporar outros recursos didáticos em sua aula, tentando fugir de um modelo exclusivamente transmissivo de ensino.

Em seguida, o licenciando acredita que sua maior falha foi em relação a um dos objetivos de ensinar física, ou seja, de formar cidadãos críticos. Essa constatação mostra que o licenciando busca atender, mais uma vez, as orientações dos PCNs (BRASIL, 1999).

Finalizando sua conclusão, o licenciando afirma que um dos seus objetivos foi atingido, o de conseguir transmitir os conceitos científicos aos alunos. Notamos que o licenciando possui uma concepção de professor como detentor dos conhecimentos, e que este deve ser passado aos alunos. E ainda comenta que pôde comprovar isso a partir de exercícios realizados em aula com os alunos. O licenciando demonstra acreditar em um tipo de avaliação que meça a aprendizagem dos alunos de forma final e mecânica.

Assim, como observamos no final da análise da aula do licenciando, percebemos também, na análise de sua reflexão, que ele possui um ethos de professor que se assemelha, em alguns momentos, ao de um professor tradicional, que detém os conhecimentos que serão passados aos alunos, e acredita em uma avaliação final que meça a aprendizagem dos alunos através de exercícios repetitivos. E, em outros momentos, se aproxima de um professor que leva em consideração as ideias dos estudantes, que procura relações com o cotidiano e que considera que o ensino de física deve contribuir com a formação cidadã dos alunos.

\section{Considerações finais}

Ao relacionarmos modelos didáticos de ensino de ciências a um aspecto da teoria do discurso, tivemos como objetivo nos inserirmos nos domínios daquilo que é mais evidente em uma aula: as trocas discursivas, nas quais se evidencia, mais pragmaticamente, o discurso do professor. Na sua prática, o professor compreende que tem um papel ético a zelar, qual seja o da transmissão bem-sucedida de saberes. Essa transmissão é desempenhada a partir de diversos outros saberes que condicionam a prática pedagógica. O diálogo é apenas um deles. Os saberes teóricos que foram construídos pela pedagogia também, incluindo os textos que orientam, sob a forma de lei, as práticas didáticas, dos quais os mais pertinentes são a Lei de Diretrizes e Bases (LDB) (BRASIL, 1996) e os PCNs (BRASIL, 1999). Esse concurso de saberes exige do falante, no caso, do professor, uma postura ética, um posicionamento, nos termos da teoria da análise do discurso, um ethos. Esse ethos consiste na construção de uma imagem condizente de professor responsável pela condução de estratégias que tornem a aula uma atividade bem sucedida. Assim, é no discurso do professor que podemos procurar as marcas que podem esclarecer as formas como se dão seus posicionamentos com relação aos conceitos, a sua didática e a sua prática. 
Hygino, C. B.; Moura, S. A.; Linhares, M. P.

As atividades planejadas e implementadas na disciplina Estratégia para o Ensino de Física I, no primeiro semestre de 2011, buscaram o alcance de um nível maior de aproximação entre os futuros professores envolvidos com a teoria, a didática e a prática.

Durante os momentos de debates em torno dos dois estudos de caso trabalhados, os licenciandos tiveram a oportunidade de refletir sobre seus próprios modelos didáticos e contrastá-los com os outros. A atividade de planejar e apresentar uma aula para seus colegas contribuiu para que os licenciandos pudessem refletir sobre sua prática.

$\mathrm{Na}$ análise da aula do licenciando $\mathrm{F}$, detectamos mesclas de concepções que apontam características dos modelos tradicional, espontaneísta e alternativo de ensino. No momento de reflexão, o licenciando $\mathrm{F}$ teve a oportunidade de perceber o que poderia ter modificado, demonstrando um processo de reflexão sobre sua prática e se aproximando, cada vez mais, de um modelo alternativo de ensino. Acreditamos que propor momentos em que os licenciandos possam elaborar e apresentar uma prática de sala de aula é um caminho para proporcionar, aos futuros professores, um conhecimento sobre seus modelos didáticos de ensino, criticá-los, propor mudanças, implementá-las e tentar novamente, assim como sustentam Porlán e Rivero (1998).

Desta forma, concordamos com Predebon e Del Pino (2009) ao reconhecermos a necessidade de se buscarem estratégias que possibilitem, ao futuro professor, uma visão mais complexa sobre sua ação e que garantam oportunidades de refletir e discutir sobre sua prática, na perspectiva de possíveis melhorias na prática docente.

Portanto, acreditamos que o aprofundamento destas questões e a proposta de novas estratégias de ensino com momentos de práticas e reflexão, nesta e nas próximas disciplinas Estratégias para o Ensino de Física II e III, podem potencializar o desenvolvimento do conhecimento profissional destes futuros professores.

\section{Referências}

BOGDAN, R.; BIKLEN, S. Investigação qualitativa em educação. Porto: Porto Editora, 1994.

BRASIL. Ministério da Educação. Lei de diretrizes e bases da educação. Brasília, 1996.

Ministério da Educação. Secretaria de Educação Média e Tecnológica. Parâmetros curriculares nacionais para o ensino médio. Brasília, 1999.

CRISTÓVÃO, V. L. L. Modelo didático de gênero como instrumento para formação de professores. In: MEURER, J. L.; MOTTA-ROTH, D. (Org.). Gêneros textuais e práticas discursivas. Bauru: EDUSC, 2002. p. 20-32.

FURIÓ, C. Tendencias actuales en la formación del profesorado de ciências. Enseñanza de las Ciencias, Barcelona, v. 12, n. 2, p. 88-199, 1994. 
Modelos didáticos na formação inicial ...

GARCÍA PÉREZ, F. F. Los modelos didácticos como instrumento de análisis y de intervención en la realidad educativa. Biblio $3 \mathbf{W}$ : revista bibliográfica de geografía y ciencias sociales, Barcelona, n. 207, feb. 2000. Disponível em: <http://www.ub.es/geocrit/ b3w-207.htm>. Acesso em: 20 maio 2007.

GARCÍA, J. E.; PORLÁN, R. Ensino de ciências e prática docente: uma teoria do conhecimento profissional. Caderno Pedagógico, Lajeado, v. 1, n. 3, p. 7-42, 2000. Disponível em: < http://www.univates.br/files/files/univates_novo/editora/arquivos_pdf/ caderno_pedagogico/caderno_pedagogico3/Ensinodecienciasepraticadocente.pdf $>$. Acesso em: 09 mar. 2010.

LINHARES, M. P.; REIS, E. M. Estudos de caso como estratégia de ensino na formação de professores de física. Ciência \& Educação, Bauru, v. 14, n. 3, p. 555-74, 2008. Disponível em: <http://www.scielo.br/pdf/ciedu/v14n3/a12v14n3.pdf >. Acesso em: 06 fev. 2014.

MAINGUENEAU, D. Análise de textos de comunicação. 6. ed. São Paulo: Cortez, 2011.

OLIVEIRA, O. B. Reflexões sobre a escrita na formação inicial de professores. Educar, Curitiba, n. 34, p. 111-126, 2009.

PÉREZ-GOMES, A. O pensamento prático do professor: a formação como profissional reflexivo. In: NÓVOA, A. (Org.). Os professores e sua formação. Lisboa: Dom Quixote, 1992. p. 77-92.

PORLÁN, R.; RIVERO, A. El conocimiento de los profesores. Sevilla: Díada, 1998.

PREDEBON, F.; DEL PINO, J. C. Uma análise evolutiva de modelos didáticos associados às concepções didáticas de futuros professores de química envolvidos em um processo de intervenção formativa. Investigações em Ensino de Ciências, Porto Alegre, v. 14, n. 2, p. 237-254, 2009.

SÁ, L. P.; FRANCISCO, C. A.; QUEIROZ, S. L. Estudos de caso em química. Química Nova, São Paulo, v. 30, n. 3, p. 731-739, 2007.

SCHÖN, D. A. Formar professores como profissionais reflexivos. In: NÓVOA, A. (Org.). Os professores e sua formação. Lisboa: Dom Quixote, 1992. p. 77-92. 